\title{
REFLEXÕES SOBRE OS MODELOS EPISTEMOLÓGICOS E PEDAGÓGICOS DE UM GRUPO DE EDUCADORES
}

FACIN, Elson Cesar

\begin{abstract}
Resumo
Nosso texto procura trazer os resultados de umapequena investigação sobre os modelos epistemológicos e pedagógicos de um grupo de educadores a partir da realização de uma pesquisa baseada em entrevistas semiestruturadas. Além disso, nós apresentamos uma pequenaretrospectiva históricadas teorias da aprendizagem mais comumente adotadas na educação e as relacionamos com as entrevistas feitas. Num processo de comparação e reflexão, procuramos verificar se os educadores entrevistados revelavam afinidade entre seu modelo pedagógico explicitado na entrevista e sua prática educacional no cotidiano escolar. Os educadores participantes da pesquisa são de uma rede municipal de ensino e possuem um tempo de magistério que varia entre um e vinte cinco anos.
\end{abstract}

Palavras-chave: Educação. Modelos Epistemológicos. Teorias da aprendizagem. Aprendizagem.

\section{Abstract}

Our article intents to bring the results of a small research on epistemological and pedagogical models of an educator's group from realization a research based on semistructured interviews. Furthermore, we present a short historical overview of learning theories most usually adopted in education and relating to the interviews. In a comparison and a reflection process, we tried to verify if the educators' answers showed affinity between the pedagogical model and their educational practice in everyday school life. Survey participants are educators in a municipal school and have a time of teaching ranging from one to twenty five years.

Keywords: Education. Epistemological Models. Theories of Learning. Learning.

\section{INTRODUÇÃo}

O viver cotidiano de educadores na prática de docência com resultados satisfatórios exige requisitos básicos: formação específica, experiência, dedicação, e, dentre outros, conhecimento em relação aos processos de ensino e aprendizagem. Como se aprende? Como se ensina? Quais ações nesse processo são as delegadas ao educador? E quais são as reservadas ao aprendente ${ }^{1}$ ? Quais tipos de aprendizagem existem (de acordo com "ideias" clássicas da literatura das 
teorias da aprendizagem e dos modelos epistemológicos)... E mais, em sua prática docente, quanto de domínio os educadores detêm em relação ao essencial ou ao básico dos quesitos necessários para uma otimizaçãode resultados da atividade cognitiva pedagógica junto aos seus aprendentes?... Estas são algumas questões para início de reflexão.

Este texto nasceu de uma atividade de pesquisa vinculada aocomponente curricular "Teoria e Prática Educativa» do Curso Mestrado em Educação (Turma X/2012) da Universidade do Oeste de Santa Catarina (Unoesc) e tem como finalidade primeira a promoção de reflexões a cerca da tarefa pedagógica.

Uma coleta de dados - através de entrevistas semiestruturadas - foi realizada para se investigar a compreensão que alguns educadores possuem (ou possuíam) sobre o processo do aprender, bem como o papel atribuído ao educador e ao aprendentenesse processo. Além disso, a coleta de dados realizada procurou estabelecer relações entre o referencial teórico lido e estudado no referido componente curricular e o conteúdo das respostas dos entrevistados. Nossa coleta de dados foi realizada com um pequeno grupo de professores; um total, inicialmente,estimado emcinco entrevistados, mas que se ampliou para sete. A pequena amostra utilizada se justifica dentro dos limites do projeto de pesquisa desenvolvido já que o referido projeto procurou ser uma atividade de pesquisa e também um aprimoramento na tarefa de pesquisar e naformação acadêmica do pesquisador - enquanto um pesquisador e um educador engajado com a investigação. Faz-se mister, aqui,ressaltar que a realização da pesquisa não teve como objetivo vincular o entrevistado participante dela à escola na qual trabalhava ou à sua prática pedagógica em alguma escola em específico, uma vez que a escolha de cada um dos educadores participantes se deu a partir de fatores relacionados ao desejo dos mesmos de participar da pesquisa, bem como da vontade deles de ser membros do grupo de entrevistados.Contudo, um critério de seleção dos atores participantes da pesquisaque teve relevância primeira foi a exigência de o entrevistado ser educador -condição estafundamental. Assim sendo, para seleção dos entrevistados, características como idade, tempo de serviço, componente curricular ministrado... não foram utilizados como parâmetros para delimitação do grupo de pesquisa; mas, dentrodas possibilidades entre os voluntários participantes,foi considerado como um elemento de seleção o tempo de serviço do docente no magistério. Dessa forma, no universo de possibilidades, foi dada 
prioridade ao convite para participar da pesquisa a: dois professores que estivessem em início de carreira, dois que estivessem em finalde carreira (acima de 20 anos em atividades de docência) e dois professores em tempo intermediário de carreira. No final das entrevistas, com um total de sete participantes, o tempo de serviço do grupo de pesquisa formado, em virtude desse número de participantes, ficou assim configurado: dois participantes com tempo de atividades no magistério entre 23 e 25 anos; três educadores com tempo de docência entre 9 a 19 anos; e dois educadores participantes com tempo de atividades no magistério entre 01 e 04 anos.

Nós, seres humanos, graças à nossa biologia e aos nossos 'mecanismos' próprios de aprendizagem conseguimos criar uma multidimensionalidadeem relação aos processos de ensino e aprendizagem que nos garante atender às peculiaridades individuais como também superar habilmente possíveis limitações (físicas, cognitivas, psicológicas...).E a natureza humana maravilhosamente nos agraciou com particularidades que não permitem que sejamos 'programados' e previsíveis (predeterminados) para a aprendizagem a exemplo de como se pode realizar a programação de uma máquina, de um computador - na comparação, considerandose que as engenhosidades eletrônicas possam 'aprender'... Contudo, mesmo resguardados nós dessa impossibilidade de programação, alguns requisitos básicos são necessários para que o ser humano (e mais especificamente aqui falando, o educando) aprenda.

Vasconcellos (2009), por exemplo, destaca como requisitos importantes no processo de aprendizagem: a) capacidade sensorial e motora do aprendente; b) capacidade de operar mentalmente; c) conhecimento prévio relativo ao objeto de conhecimento; d) acesso ao objeto de conhecimento (informação nova); e) desejo de querer conhecer o objeto; f) agir sobre o objeto e g) expressar-se sobre ele.

Além dos requisitos destacados acima, é necessário enfatizaroutra importante dimensão no processo de aprendizagem: a mediação. Para Vasconcellos (2009), a mediação desempenha um papel muito importante no processo de aprendizagem, uma vez que a aprendizagem é mediada socialmente.

A mediação envolve a utilização de instrumentos culturais (físicos e, sobretudo, simbólicos). Além desta mediação - considerada mais geral - poderá haver uma modalidade de mediação tida comopresencial. Interessa-nos em 
particular este aspecto da mediação, porque ele nos faz recobrar a ideia do mediador que tradicionalmente conhecemos como professor. Então, neste aspecto, é importante a partir de nossa pesquisa feita,visualizar o papel que o educador tem de si (ou julga ter) frente aos processos de ensino e aprendizagem.

Ainda, outro ponto que merece destaque em relação à aprendizagem é que ela é uma atividade contínua. Conforme Valente (2001), ela se inicia nos primeiros minutos de vida e se estende ao longo desta.A aprendizagem, portanto, não se limita ao período escolar; distante disso, ela é inerente a nós e se dá em todos os momentos de nossa vida. Portanto, é evidente que ela também não fica restrita a determinados momentos da aula no período escolar como costuma ser um tipo de ideia presente no senso comum do cotidiano pedagógico das escolas.

Ter uma compreensão melhorada sobre como se processa a aprendizagem, sobre sua natureza, certamente servirá para que o educador ampliepositivamente os resultados no seu fazer pedagógico e conduza o aprendente por produtivos caminhos do saber;conduza-o por significativos caminhos da cognição. Porque o desafio da educação frente à constituição, formação e organização política e social da humanidade exige uma reflexão sobre os processos educacionais, sobre a aprendizagem; uma vez que muito do que somos e de como vivemos passa pela instituição formalde conhecimento: aescola. Com o olhar voltado para esta formação humana, nas palavras de Valente (2001), é preciso que a relação entre conhecimento-educador-aprendente seja uma relação de construção e desenvolvimento de competências e habilidades; é preciso que o aprendente não seja apenas um mero consumidor de conhecimento, mas que, a partir do conhecimento, ele possa continuar a aprender ao longo de sua vida (e, naturalmente, contribuir para transformar a sociedade em que vive em um espaço social melhor do que ele o é).

Ainda mais que a aprendizagem se constituiu (se constitui) - como mencionado acima - numa dimensão essencial da nossa atual sociedade. "Aprendemos e ensinamos porque precisamos resolver problemas reais e interagir com as pessoas" (VALENTE, 2001, p. 10).

Para Pozo (2004, p. 9), sociedade e aprendizagem disputam forças. Conforme suas ideias, vivemos em uma sociedade da aprendizagem em que aprender constitui uma exigência social crescente que conduz a um paradoxo: "[...] cada vez se aprende mais e cada vez se fracassa mais na tentativa de aprender." 0 
autor atribui como causa desse insucesso a imensa quantidade de informação que temos ao alcance de nossas mãos e olhos; entretanto é necessário saber gerenciar esse fluxo de informações, é preciso dar sentido à informação, é imperativo ter-se a capacidade de assimilação críticada informação - proceder crítico esse que deve ser objeto nas aulas com os aprendentes. É preciso que tenhamos uma escola com uma educação que fomente nos aprendentes capacidades de gestão de conhecimento ou, como sugere Pozo (2004, p. 10), capacidade de "gestão metacognitiva".

Sobre a aprendizagem, ainda, importa destacar que, de acordo com Furtado (2010), ela é um processo interno que não se mostra observável na maior parte dos seus momentos e nem se resume à mudança de comportamentos observáveis. É um complexo processo que envolve a "[...] pessoa em todas as suas dimensões: afetiva, cognitiva e psicossocial" (FURTADO, 2010, p. 48). E, um antagonismo, pode ser considerada uma 'ameaça' à pessoa, porque ao mesmo tempo em que é uma oportunidade de crescimento, também coloca em risco sua identidade, provocando medo e resistência, abalando sua segurança pessoal.Contudo, aprender, conforme Furtado (2010), implica em se abrir para o futuro: pois, aprender tem a ver com a concepção filosófica de afirmação de vida.E o autor acrescenta que o desejo de aprender - a "disposição para aprender" (DPA) - é ligadaa três fatores principais: a) o momento de vida da pessoa, incluindo sua mobilização emocional para o aprender; b) a história pessoal de aprendizagem - sucessos, fracassos...; e c) a percepção do contexto de aprendizagem - relação tecida com a cultura do ser humano aprendente.

\section{GEOGRAFIA DA PESQUISA}

A seguir, para uma melhor compreensão do leitor, apresentamos resumidamente a geografia da pesquisa realizada.

Nosso objetivo geral debruçou-se sobre a identificação de consonância ou não entre a prática e a teoria nos modelos pedagógicos adotados pelos educadores no cotidiano escolar em comparação com os modelos epistemológicos clássicos do pensamento humano aplicados à educação. E a partir deste objetivo primo, procuramos: 1) verificar na concepção dos educadores entrevistados qual é o papel atribuído no processo de ensino/aprendizagem aos educadores e aos aprendentes; e 2) compor a partir das respostas dadas pelos entrevistados um paralelo entre as 
respostas e o referencial teórico estudado sobre o processo de aprendizagem em termos pedagógicos.

\section{METOdologia E ESTRATÉGIA DE AÇÕES}

Nosso ponto de partida para a coleta de dados foi convidar alguns professores para participar de entrevistas semiestruturadas. A ideia inicial era conseguir um número voluntário de cinco participantes. Entretanto, para nossa surpresa agradável, dispuseram-se a participar dela seteeducadores.

As entrevistas semiestruturadasforam realizadas individualmente com cada participante e gravadas (captação da voz com dispositivo de gravação digital).

No início de cada entrevista, o pesquisador explicou a cada um dos educadores participantes os objetivos da pesquisa, bem como a importância da realização dela para o aprimoramento da vida acadêmica do pesquisador. Então, cada educador entrevistado recebeu impressos para leitura e preenchimento: 1) Carta para obtenção do Consentimento Livre e Esclarecido para pesquisas que envolvam adultos, questionário e avaliação e Termo de Consentimento Livre e Esclarecido; 2) um roteiro das atividades de pesquisa para levantamento de alguns dados pessoais e profissionais (sexo, idade, tempo de serviço...)

Depois dos esclarecimentos sobre a pesquisa, cada um dos entrevistados sem conhecer as perguntasantes de serem feitas -respondeu ao pesquisador às seguintes questões:

1. Como você define a aprendizagem?

2. Qual o papel do professor no processo de aprender?

3. Qual o papel do aluno nesse processo?

4. Que recursos você utiliza para que a aprendizagem ocorra? Por que você os utiliza?

O pesquisador fez cada uma das perguntas oralmente e, se julgou necessário, realizou algumas intervenções junto à fala (ao depoimento) do educador entrevistado. Depois de realizadas as gravações das entrevistas, cada uma delas foi transcrita, procurando manter uma fidelidade literal (exceto em algumas variações linguísticas orais como a supressão de unidades em final de alguns verbos, por exemplo: vô - grafado na transcrição como"vou", estudá - grafado como"estudar"...).É importante uma ressalva: a transcrição não ficou vinculada às 
normas de transcrição grafemática de entrevistas. Nós nos justificamos: o propósito da transcrição foi dar base para a elaboração de uma tabela de análise com a essência da resposta de cadaentrevistado, assim, optamos por transcrever toda a entrevista para, a partir da transcrição, realizar os devidos recortes - que se tornaram a fonte de pesquisa.

A partir dessa tabela de dados com a essência da entrevista foiformado 0 'corpus' da base de dados para análise. A análise das respostas (a essência das entrevistas)foi realizada da seguinte maneira: a partirde um referencial teórico lido/estudado,realizamos uma análise buscando identificar as teorias de aprendizagem que guiam o fazer pedagógico de cada um dos entrevistados, bem como, se há coerência entre a prática do fazer pedagógico do educador e o seu discurso (colhido a partir da entrevista).

Além dos dados referentes à prática da docência, foi composta umaoutra tabela com dados dos professores entrevistados. Essa tabela sintetizou dados como: sexo, idade, tempo de docência, formação...

\section{DEBRUÇAMENTO Sobre os dados Coletados ${ }^{2}$}

Nosso propósito principal neste estudo partiu da verificação de consonância (ou não) entre a teoria e a prática nos modelos pedagógicos/epistemológicos adotados pelos educadores no seu fazer educativo do cotidiano escolar. Assim sendo, cabe-nos antes de qualquer ação, apresentar uma síntese em breve quadro com um resgate das ideias consagradas dos principais modelos epistemológicos, pedagógicos bem como das teorias da aprendizagem ligadas a eles.

\begin{tabular}{|c|c|c|}
\hline $\begin{array}{l}\text { Modelo } \\
\text { epistemológico }\end{array}$ & Modelo pedagógico & Teorias da aprendizagem \\
\hline a) $\widetilde{S}^{\text {Empirismo }} 0$ (sujeito) (objeto) & 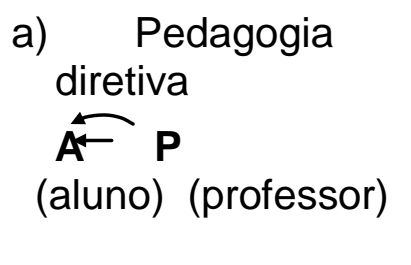 & $\begin{array}{l}\text { a) Teoria } \\
\text { comportamental/ } \\
\text { Behaviorista } \\
\text { E R R - Reforço } \\
\text { (estímulo) (resposta) }\end{array}$ \\
\hline $\begin{array}{l}\text { b) Apriorismo } \\
\text { (inatismo) }\end{array}$ & $\begin{array}{l}\text { b) Pedagogia não- } \\
\text { diretiva }\end{array}$ & $\begin{array}{l}\text { b) Gestalt/Humanista } \\
\text { (Köhler, Rogers /Teoria } \\
\text { figura/fundo) }\end{array}$ \\
\hline
\end{tabular}




\begin{tabular}{|c|c|c|}
\hline $\begin{array}{l}\text { Modelo } \\
\text { epistemológico }\end{array}$ & Modelo pedagógico & Teorias da aprendizagem \\
\hline$\underset{\text { (sujeito) (objeto) }}{\overparen{S} 0}$ & $\begin{array}{l}\overparen{\mathbf{A} \rightarrow} \mathbf{P} \\
\text { (aluno) (professor) }\end{array}$ & \\
\hline c) $\overbrace{\substack{\text { mo } \\
\text { (sujeito) (objeto) }}}^{\text {Construtivis }}$ & $\begin{array}{l}\text { c) Pedagogia } \\
\text { relacional } \\
\overparen{A} \mathbf{P} \\
\text { (aluno) (professor) }\end{array}$ & 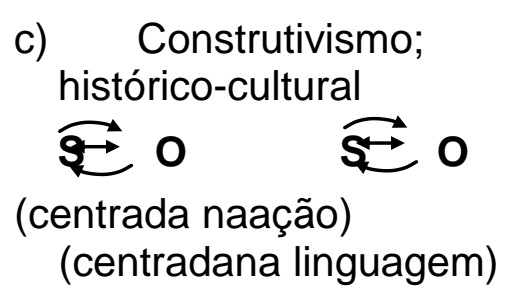 \\
\hline
\end{tabular}

Observação: as setas no quadro acima indicam a origem e o destino das ações.

Tabela de autoria da Profa. Dra. Maria Teresa Ceron Trevisol ${ }^{3}$

Seguindo em linhas gerais com uma ideia de síntese, apresentamos algumas ponderações sobre os modelos epistemológicos relacionados aos modelos pedagógicos e às teorias da aprendizagem conforme quadro anterior.

Iniciamos compondo uma breve síntese sobre o empirismo.

$\mathrm{Na}$ epistemologia empirista a fonte do conhecimento humano está na experiência adquirida em função do meio físico com mediação dos sentidos. São os sentidos a porta de entrada para a impressão do conhecimento no sujeito - uma "tábua rasa", "folha de papel em branco".

A partir do desenvolvimento da teoria comportamental (behaviorismo), a aprendizagem é entendida como uma modificação no comportamento provocada pelo "agente que ensina", utilizando estímulos reforçadores adequados sobre o "sujeito" que "aprende". Desta forma, a pedagogia para os empiristas é diretiva, ou seja,o aprendizado do aluno acontece somente se o professor ensina. Assim sendo,há a crença numa transferência de conhecimento. Na prática de ensino, então, para a pedagogia diretiva, entra em jogo o mecanismo de estímulo $\rightarrow$ resposta $\rightarrow$ (Reforço).Desta maneira, o professor "repassa 0 conhecimento" (treino/repetição/reprodução) e utiliza o reforço como um condicionante para aumentar a probabilidade de emissão da resposta desejada em situações futuras.

São nomes importantes relacionados ao desenvolvimento do comportamentalismo iniciado com Watson: o do fisiólogo russo Pavlov (1849-1936), 
do psicólogo norte-americano J. B. Watson (1878-1958) e o nome do psicólogo norte-americano Skinner (1904-1990).

O segundo modelo epistemológico do quadro apresentado, oapriorismo, por sua vez, representa uma oposição à epistemologia empirista,pois,considera que o indivíduo em seu nascimento já traz consigo determinadas as condições de conhecimento e aprendizagem. Essas condições se manifestarão imediatamente (inatismo) ou progressivamente ao longo do processo geral de maturação do ser. Um ponto importante ressaltado neste modelo epistemológico é que a atividade de conhecimento é exclusiva do sujeito, o meio não tem participação; quer dizer, a origem do conhecimento está no próprio sujeito.

$\mathrm{Na}$ concepção apriorista, a partir da teoria da forma ou da Gestalt (conhecimento visto das partes para o todo), o conhecimento é visto como algo inerente ao sujeito e que necessita ser despertado. Uma vez que o raciocínio é visto como inato; o ensino teria a função de expandir o que já por si está na constituição hereditária. Cumpre ao professor na sua atividade pedagógica estimular o aluno para que o conhecimento surja, aflore, se efetive.

A pedagogia apriorista, como destacada no quadro anterior, é não-diretiva. Por conseguinte,ao professor é conferida a tarefa de ser um auxiliar, um facilitador para o aluno. Sendo assim, a intervenção do professor em relação ao processo de aprender é a mínima possível.

Nome importante relacionadoà teoria da Gestalté o do psicólogo alemão Köhler (1887-1967), e em relação à pedagogia não-diretiva tem-se o nome do psicólogo norte-americano Carl Rogers (1902-1987).

No terceiro modelo epistemológico apresentado no quadro anterior - o construtivismo - a relação entre sujeito $(S)$ e objeto $(O)$ é "recíproca"; ou seja, o conhecimento será constituído na (e pela) interação entre sujeito e objeto.

Um dos principais nomes ligados à teoria construtivista é o do epistemólogo suíço Jean Piaget. Ele desenvolveu a teoria da epistemologia genética. Para Piaget, a inteligência se caracteriza no principal meio de adaptação do ser humano porque possibilita a construção de estruturas mentais para serem aplicadas a estruturas do meio (o que, também, possibilita a elaboração de novas estruturas). De acordo com Piaget, na interação entre sujeito e objeto $(S \leftarrow \rightarrow O)$ na construção do conhecimento há dois processos envolvidos: a assimilação - transformação objetiva do mundo em que o sujeito realiza ações para poder interpretar e internalizar o objeto em suas 
estruturas cognitivas; e a acomodação - alteração das estruturas cognitivas do sujeito para poder compreender o objeto;essa é uma transformação em si mesmo. Segundo Piaget, são esses dois processos os responsáveis pelo processo de desenvolvimento cognitivo do sujeito (ser humano).

Dessa interação entre sujeito/objeto, a teoria de Piaget considera que o sujeito se constrói por meio de sua própria ação, relacionando-se num tempo e espaço com meio social, econômico e cultural. Assim sendo, o sujeito é considerado "um sujeito histórico, cultural, social, político. Para Piaget, as estruturas não estão pré-formadas no sujeito, este as constrói na medida das necessidades e das situações. A experiência não é uma recepção passiva, é um processo ativo" (PONTES, REGO\& SILVA JR., 2006, p. 68).

Do modelo epistemológico construtivistaemanam (ou dele se aproximam) as teorias cognitivistas: a) verbal significativa (Ausubel); b) construtivismo (Piaget); c) sócio-contrutivista/histórico-cultural (Vygotsky).

A seguir, faremos uma breve abordagem sobre cada uma dessas teorias.

\section{Verbal significativa}

Para o psicólogo norte-americano, David Ausubel (1918-2008), a aprendizagem está ligada a conceitos e, em se tratando de aprendizagem escolar, por exemplo, o conhecimento prévio do aluno é a chave para a aprendizagem significativa.

Segundo as ideias de Ausubel, uma nova informação se relaciona com um aspecto relevante da estrutura de conhecimento (estruturada em forma de conceitos) que o indivíduo possui. Nesse processo de formação de conhecimento, são fatores importantes para que a aprendizagem ocorra: material potencialmente significativo e disposição para aprender.

No processo de aprender relacionado à escola, Ausubel considera importante o professor trabalhar com organizadores prévios ("pontes cognitivas" que têm como papel ligar o conhecimento desconhecido ao que o aprendiz já sabe). Ao professor é reservada a função de programar, sequenciar os conteúdos e, ao aluno, uma atitude ativa de descobridor, envolvido no processo de construção de seu conhecimento entre o que ele já possui internalizado e o que lhe é novo.

\section{Construtivismo}


Jean Piaget (1896-1980) não foi um pedagogo, mas - entre outros títulos um biólogo que se dedicou a observar com rigor o processo de aquisição do conhecimento no ser humano, particularmente na criança. Ele marcou a educação ao mostrar que a criança não pensa como o humano adulto, mas vai construindo seu próprio aprendizado (em etapas).

Piaget se ocupou da observação do comportamento infantil atento às concepções da criança em relação ao tempo, ao espaço, à causalidade física, ao movimento e à velocidade. O campo de estudo criado por este cientista ficou conhecido como epistemologia genética - uma teoria do conhecimento que é centrada no desenvolvimento natural da criança. Piaget enuncia que o conhecimento na criança se dá por descobertas - que ela própria faz. O conhecimento resulta da interação do sujeito e o meio - através de uma ação (física e lógico-matemática).

Levando Piaget para a sala de aula, temos o professor como responsável pelo desequilíbrio da estrutura de pensamento do aluno. O professor deve provocar a busca pelo conhecimento.

\section{Socioconstrutivista/histórico-cultural}

A teoria que nasce das reflexões do psicólogo bielo-russo Lev Vygotsky (1896-1934) - teoria da aprendizagem caracterizada como sócioconstrutivista/histórico-cultural. Vygotskty atribuiu um papel preponderante às relações sociais no processo de desenvolvimento intelectual. Para ele, a aprendizagem (enquanto construção do conhecimento) tem grande ênfase no social, nos processos interpessoais (em oposição às ideias fundamentais de Piaget que atribuem ênfase aos processos internos; contudo, apesar disso, não são atribuídos antagonismos e oposições às reflexões dos dois).

Na compreensão de Vygotsky, o homem se constrói como um ser que está em contato com a sociedade. Portanto, a formação se dará através de uma relação dialética entre homem e sociedade - o homem modifica o ambiente e é modificado por ele.

Um outro conceito-chave na teoria de Vygotsky diz respeito à mediação: uso de instrumentos técnicos utilizados na relação do indivíduo com o mundo; instrumentos agrícolas que transformam a natureza, por exemplo, e, a linguagem instrumento utilizado no relacionamento social e que carrega consigo conceitos consolidados da cultura à qual o indivíduo pertence. 
Em relação à educação, é importante frisar que o professor é concebido como um mediador - todo aprendizado é necessariamente mediado - como o responsável por planejar intervenções (na relação do aluno com o conhecimento). Ao aluno, por sua vez, compete uma postura ativa frente ao conhecimento enquanto se desenvolve aprendendo e aprende se desenvolvendo. Nesse processo, a linguagem possui uma valoração importantíssima.

Ainda, em relação à teoria de Vygotsky aplicada à sala de aula, é necessário destacar o conceito de Zona de Desenvolvimento Proximal (ZDP) - que se refere à distância de desenvolvimento real do aluno e aquilo que ele tem potencial para aprender; potencial que é demonstrado pela capacidade de desenvolver uma competência com a ajuda de alguém mais experiente (um colega, um adulto, o professor, por exemplo).

Em nosso texto, então, depois desse breve resgate histórico de alguns pontos da teoria que buscou (e busca) uma melhor compreensão a respeito da Educação, ousamos nos debruçar e interpretar as respostas dadas pelo grupo de professores entrevistados a cerca do aprender; dos papéis do educador e do aprendente no cotidiano pedagógico frente à aprendizagem, bem como, dos recursos utilizados pelo educador para uma efetiva aprendizagem do aprendente.

Nessa nossa tarefa de interpretação das respostas não pretendemos emitir juízo algum de valor sobre o trabalho pedagógico do educador - mesmo porque não nos caberia penoso e estéril trabalho - nem, tampouco, imputar um modelo epistemológico ou pedagógico, ou, uma teoria de aprendizagem ao educador entrevistado. Primeiro, porque as perguntas da entrevista semiestruturada não dão conta de um levantamento desta natureza; segundo, porque nosso propósito inicial não é esse. O que desejamos é observar se nas respostas dos professores - nas quatro respostas dadas - há uma linha teórica mais definidaperpassando os seguinte elementgšué aprender

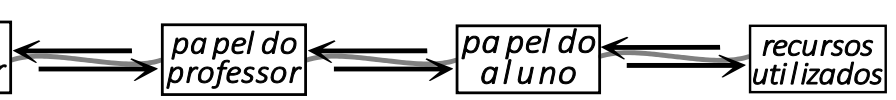

Em nossodebruçamento sobre as repostas dadas pelos entrevistados utilizamos letras para identificar os professores participantes e números para indicar a qual pergunta a resposta dada se refere. Assim, por exemplo, a identificação A1 
corresponde à resposta dada pelo entrevistado "A" para a pergunta "1".

Ainda, fazendo-se uma média do tempo das sete entrevistas colhidas, cada uma delas teve um tamanho médio de aproximadamente 4 min40seg. Há um tempo extra em cada uma das gravações, geralmente no final, mas que não foi transcrito para fins específicos neste trabalho; neste tempo extra, pesquisador e entrevistado têm uma conversa mais informal e menos objetiva em relação à entrevista feita, em relação à prática pedagógica do entrevistado, em relação ao exercício da docência...

\section{Pergunta 01 - o que é aprendizagem?}

Nas entrevistas realizadas, a primeira pergunta trouxe como respostas - para a maioria dos professores - que a aprendizagem está relacionada a processos internos significativos relacionados à vivência do aprendente:

envolve a questão de autoestima, a questão... ãh... de vivência, né de convívio familiar, de vivência do aluno, né? (A1)

a gente tem que ver o aluno, ãh, ou aprendizagem no sentido amplo. [...]e não só aquele conteúdo que você tá ali ensinando, mediando. (B1)

Pra mim ele... a aprendizagem é um processo longo por toda a vida. Mas inicia-se a partir da... do momento que a criança começa a identificar símbolos, desenhos, letras... (C1)

A aprendizagem é um processo que todo ser humano... tem desde o momento que nasce - até no ventre materno, nós já estamos em processo de aprendizagem. (D1)

Aprendizagem, pra mim, é tudo o que eu absorvo, que eu utilizo, porque nem tudo o que eu absorvo é, é útil pra mim. Então, pra mim, não se configura aprendizagem. (G1)

Certamente que o recorte das respostas acima deixa perceber que o tom da resposta de cada um dos educadores se afina à aprendizagem no âmbito escolar e não tão somente à aprendizagem enquanto processo na vida do ser humano. $E$ esse teor das respostas é justificável, já que a natureza de nossa pesquisa (em um ambiente escolar) se encarregou de dar esse tom. 
É válido também ressaltar que uma das respostas dadas faz-nos perceber que o entrevistado tem a aprendizagem ligada à figura do educador, ao repasse de conteúdos - se assim podemos dizer:

Eu defino a aprendizagem... os alunos aprender... o que a gente está ensinando pra eles, né? O que a gente tá passando pra eles. Então, se você passou um conteúdo e eles conseguiram pegar, então a aprendizagem deles está, né... indo como a gente quer, né? (F1)

\section{Pergunta 02 - qual é o papel do professor no processo de aprender?}

Nas respostas a esta segunda pergunta, a maioria dos entrevistados revelou que vê no educador a responsabilidade deum mediador. A mediação faz referência às ideias vygotskianas, entretanto, as respostas dos entrevistados não são suficientes para uma caracterização do entrevistado como partícipe de uma educação voltada para uma prática vygotskiana de ser. Contudo, em outras respostasdadas - a respeito dos recursos utilizados para que a aprendizagem aconteça e o porquê da utilização dos referidos recursos - os entrevistados deixaram transparecer mais sua preocupação em fazer com que o aprendente seja um responsável ativo no processo de aprendizagem, podendo ser assim uma afinação em relação às ideias de Vygotsky.

A seguir, recortes de respostas dos entrevistados que nos fazem notar traços de uma postura vygotskiana no jeito educador de ser:

Ah, ele seria na verdade um, um mediador, né, porque... ah, um orientador. Nesse sentido. Ãh, ele seria um orientador. (B2)

Eu, eu vejo o professor como mediador. Que é o professor que vai fazer com que a criança avance de onde ela está... pra onde... pra série que ele tá trabalhando, por exemplo. (C2)

Na verdade, o professor é o mediador desse processo. Porque, como a aprendizagem é algo inerente ao ser humano que ele está aprendendo todo, em... a todo momento. Sempre! Né? Está em aprendizagem. Então o professor serve como mediador. Ele vai auxiliar o aluno nessas descobertas, né? E de como isso pode ser usado e potencializado no seu dia a dia. (D2) 
Eu acho que o professor tem que ser um norteador. Nem, ãh... extrapolar de um lado nem do outro. Ele tá ali para mediar e nortear o processo de aprendizado do aluno (E2)

O professor é uma ponte. E, ele, ele tem que buscar ser facilitador. Por exemplo. Nem todo mundo absorve as coisas da mesma maneira. (G2)

Uma anotação oportuna a se fazer a partir das entrevistas realizadas é que ao término da resposta da última pergunta feita a cada entrevistado, ainda com o gravador ligado e num tom de conversa informal com o pesquisador, três dos participantes declararam enfaticamente orientar sua prática pedagógica a partir da teoria de Lev Vygotsky.

\section{Pergunta 03 - qual é o papel do aluno nesse processo (de aprender)?}

Em relação a essa pergunta, a resposta da maioria dos entrevistados se dirige para o aprendente como um coparticipante no processo de aprendizagem em sociedade com o educador (um mediador).

Se o professor motiva esse aluno, ele vai ter uma resposta, isso...

pra mim é automático. [...] Mas o aluno também, nos dias de hoje... isso é bastante complicado, mas ele precisa ter vontade e sempre enxergar algo mais naquilo que tá aprendendo. O professor ser um motivador. (A3)

$\mathrm{O}$, e... ele seria também um participante, né, de... trazendo o conhecimento dele e um aprendiz, também... Tá.. (B3)

O aluno é aque... é o... é a... é o... é a... é o elemento que vem pra que a escola se faça essa ponte entre a aprendizagem formal - que é o papel do professor, da leitura e da escrita, então ele vem pra que o professor possa ajudá-lo nesse sistema e que esse.. essa construção da aprendizagem seja dentro de uma linha formal que é o papel da escola.. (C3)

de aprendiz, mas além de ele estar na condição de aprendiz, ele também... ãh... tem o seu papel... ãh... de mediador, porque as... as coisas que ele traz do seu cotidiano, da sua prática, daquilo que ele vivencia, ele tem como interagir com o outro e acabar nesse momento também despertando outras descobertas com o qual ele interage, inclusive com o próprio professor. (D3) 
$\mathrm{O}$ aluno tem que caminhar junto com o professor. Tem que cooperar, né, tem que... é... prestar atenção, tem que se doar, também. (F3)

O papel do aluno... O aluno... ele já vem com seu... com a sua história. Então ele já vem pra dentro da sala de aula como cidadão, né? Ãhn... mesmo que ele não se coloque no papel de cidadão. Ele já é. Então, assim, muitas vezes a gente fa... faz as coisas na sala de aula. Se...sem se dar conta de que ali dentro tem seres históricos e cada um vai se relacionar com o que a gente passa de uma forma diferente... O papel dele, primeiro é estar ali. (G3)

Alguns dos entrevistados fizeram, em suas falas, ressalvas em relação ao compromisso do aprendente frente à sua aprendizagem: a necessidade de que ele se dedique, que tenha empenho. Furtado (2010) - como já destacamos anteriormente em nosso texto - fala sobre a "disposição para aprender" (DPA); e um dos pontos é justamente a mobilização emocional para o aprender.

Acreditamos que as repostas dadas pelos entrevistados frente a essa pergunta, em sua maioria, quando relacionadas ao papel do educador no processo de aprender estão em sintonia com o modelo epistemológico construtivista. Contudo, se também levarmos em consideração os recursos (pedagógicos) utilizados pelos entrevistados conforme as respostas dadas por eles, essa nossa caracterização fica menos evidente, já que os entrevistados não discorreram sobre sua prática pedagógica.

\section{Pergunta 04 - que recursos você utiliza para que a aprendizagem ocorra e por que você os utiliza?}

Em respostas a essa quarta pergunta, a maioria dos professores apontou recursos visuais referentes a multimeios: eslaide e vídeo (recursos normalmente aliados a tecnologias como computador e projetor multimídia pelo que depreendemos das entrevistas realizadas e também em razão de escola em que os entrevistados trabalharem dispor de inúmeros equipamentos com computador e projetor conjugados com acesso à internet).

E nos chamou atenção um dos entrevistados apontar como recurso que utiliza em sua prática pedagógica a linguagem (referência à língua). É curioso somente uma ocorrência; pensamos que mais educadores deveriam ter se dado conta desse recurso, especialmente os que se afinam com a teoria de Vygotsky. Mas, também, 
em relação à linguagem, importa frisar a resposta de um dos entrevistados que disse ancorar sua prática pedagógica no estímulo à leitura - certamente a língua nas aulas desse educador ocupa papel importante e com feições socioeducativa.

A seguir, apresentamos recortes dos depoimentos dos entrevistados no tocante aos recursos utilizados:

Eu acho que os instrumentos são variados, né. Cabe a gente saber o momento de... certo de utilizá-los pra cada assunto. Então, eu gosto muito da questão visual, né? Mostrar num... num eslaide, numa filmagem, né? Ãh, ãh, ãh... ou até u-uma-ma... através de, de, de fotografias, né? Aquilo que a gente tá expressando como, como orientação pra aprendizado do aluno. É...é...é... A atividade eu acho fundamental. O aluno exercitar aquilo que ele tá, ãh... recebendo de informação através de pergunta-resposta ou dos mais variados.... (A4)

Nós usamos, eu uso vídeos, tá. Eu gosto muito de trabalhar com mapas, tá. Porque ali 0 aluno tá visualizando também. [...] E é uma voz diferente, é uma coisa diferente, é uma imagem diferente que uma visualização diferente que ele tem. [...] Pra os alunos se interessar, pra despertar o interesse deles... Que nessa faixa de idade que eu trabalho tem alunos que tem muito interesse. Eles pedem, eles questionam, eles participam, eles, né... [...] Eles gostam de ãh... sair da carteira ir lá no mapa ver aonde que tá localizado o que a gente está estudando e tal. [...] Eles adoram fazer um trabalho como nós fizemos sobre as células, daí eles se reprodu... reproduzirem as células de uma forma diferente que eles usaram diversos tipos de materiais... [...] Né, usar outros recursos não só o mapa, o vídeo, como outros materiais. Como em geografia eu trouxe vários tipos de pedras, de minérios, né. Trazer o que é concreto pra ele ver e tal. Observar... no concreto e associar, colocar, por exemplo, o que ele tá vendo com ah, o conteúdo que ele vai ter. Pra ele pensar um pouco... (B4)

Bom, primeiramente nós usamos a linguagem. Que é o primeiro recurso que nós temos pra trabalhar com o aluno. De... segundo recurso é o quadro de giz e o... e o giz que é uma coisa que já é precária mas ainda a gente faz usos. E as tecnologias como multimídia, é se... rádio, gravador, $C D$, jornais, livros de literatura... músicas, letras de músicas. Essas são os recursos que nós temos, hoje, que podemos auxiliar o aluno a construir a leitura e a escrita. (C4) 
Os recursos que eu utilizo é muito a questão da pesquisa, da busca, né? Então muita questão de livros, né, que as crianças podem ter à mão. Outros recursos, outros gêneros textuais como jornal, como carta, como revista, ãh... que na verdade o jornal é um suporte, mas a notícia em si. Ah... a carta, ah... o própria pesquisa na internet, o computador, o multimídia. (D4)

Ai, eu não utilizo só um não. Eu utilizo várias entre ele... várias ferramentas pra esse processo, né? $\mathrm{E}$ essas ferramentas, elas são utilizadas de acordo com a realidade de cada aluno, da escola, da região. Então, esse processo, ele... é. é... essa ferramenta não depende só é... do quadro negro. [...] Ahã. Mapas é um deles. Eu gosto muito de trabalhar com... realmente até filme pra mostrar as imagens dele. (E4)

os menores... é... eu tenho que fazer mais desenhos, tenho que passar mais conteúdo no quadro, eles querem ter coisas no caderno... [...]Então, eu já trouxe multimídia e tentei passar em eslaides, que é uma coisa rápida e não cansa. Só que eles não gostaram daquilo. [...]A metodologia pra eles é muito rápida. Eles querem uma coisa assim... Então eles gostam que eu peça pra eles desenhar... né? Os desenhos mais que... os animais, as plantas... todas elas têm suas, né? Assim são coisas mais difíceis. Então, eles gostam. Já os mais velhos, eu já posso trazer... (F4)

Eu sou uma figura lúdica. Hã... e eu estimulo a leitura... demais. Mas não só porque eu tô trabalhando com língua portuguesa. Eu estimulo a leitura para todas as áreas afins, todas as áreas. Porque a base de tudo é leitura. Se você sabe interpretar um texto, você vai abrir, você vai dilatar $0 . .$. a tua mente pra matemática, pra química. Tudo é interpretação. Tudo é interpretação. Pra você pegar um ônibus você tem que estar interpretando... lá pra onde vai, o horário que ele vai passar... [...] Eu... procuro fazer projetos que estimulem a leitura. Estimulo a leitura de todas as formas que eu posso na sala de aula. [...] eu... a minha ferramenta assim bem... é, é.... bem utilizada, é a leitura. Essa é a minha ferramenta assim e elas... E as coisas lúdicas, assim. (G4)

6 CoNCLUSÃO: EM SíNTESE DE ALGUMAS IDEIAS 
No decorrer de nosso texto fizemos apontamentos e reflexões a respeito do processo de aprendizagem (especialmente com foco voltado para o aprendente) e também de elementos que envolvem o processo do aprender.

Ainda, apresentamos sucintamente uma caracterização dos modelos epistemológicos:a) empirismo, b) apriorismo, c) construtivismo e dos modelos pedagógicos que os têm como base, bem como as teorias da aprendizagem: 1) comportamental; 2) Gestalt/humanista; 3) verbal significativa, construtivista, socioconstrutivista/histórico-culturalligadas a esses modelos epistemológicos.

Em nosso ponto de partida desse trabalho - a verificação da consonância entre a prática pedagógica e os modelos pedagógicos adotados pelo professor julgávamos que não encontraríamos uma afinação entre teoria e prática no cotidiano pedagógico dos educadores participantes da pesquisa, contudo, a maior parte dos entrevistados mostrou coerência entre sua prática pedagógica e a teoria que subjaz sua prática (acreditamos que a maioria se inclina a uma pedagogia com feições vygotskiana).

Em relação à nossa atitude de julgar que não encontraríamos a partir da pesquisa realizada afinação entre teoria e prática, nosso julgamento não é em razão de descrédito no que se refere às atividades de docência dos entrevistados ou o resultado de uma atitude de prepotência nossa, mas porque estudos e pesquisas comprovam que a educação Nacional, de maneira geral, se apresenta carente de embasamento teórico que sustente a prática pedagógica dos educadores. Em Laranjeira (2000, p. 114), encontramos referência a essa lacuna no cotidiano pedagógico: "[...] nos levou à conclusão de que: é tanto na ausência de um contexto de reflexão epistemológica como na ausência de um contexto de exercício cognitivo de construção de conceitos e aplicação de princípios, que o professor pode estar sendo levado a assumir noções do senso comum." Em Hernández (1998), também notamos reflexões a cerca da necessidade premente de haver uma base teórica a dar suporte à prática do educador no seu fazer pedagógico cotidiano.

Acreditamos que esta atividade de pesquisa tenha sido muito significativa para nosso crescimento acadêmico como pesquisador - uma vez que trouxe a prática de coleta de dados a partir de entrevistas semiestruturadas - e também contribuiu para reflexões e nossa ampliação do conhecimento sobre o processo de ensino-aprendizagem, uma vez que foi necessário que realizássemos inúmeras leituras relacionadas à teoria epistemológica educacional. 
Ainda, cremos que a pesquisa realizada pôde se constituir em instrumento de reflexão sobre os processos de ensino e aprendizagem por parte dos participantes dela, bem como promover o aprimoramento e ampliação dos conhecimentos que os entrevistados (possuíam) possuem em relação à aprendizagem e ao ensino, uma vez que o próprio ato de falar sobre a prática da docência conduz o pensamento a uma análise de teoria e prática, conduz a um refletir sobre, a um repensar a respeito de... Também, como nossa pesquisa se propôs a retornar os resultados observados aos seus participantes, ela também se configurou mesmo num instrumento de formação.

Notas

1 Neste trabalho, a partir de leituras e da experiência na Educação, a adoção da palavra "aprendente" em lugar de "aluno" ou "educando" pareceu mais significativa e adequada. Em nosso ver, aprendente faz uma melhor referência à dimensão de aprendizagem que conjuga fatores cognitivos, afetivos, pessoais - o Eu, e sociais - o Outro, a cultura.

${ }^{2}$ Mesmo querendo ver a Educação com outro olhar, por exemplo, repensando o uso de 'termos' clássicos como "aluno", "professor", nosso texto segue trazendo esses e outros nomes tradicionais (sujeito, indivíduo...) uma vez que a redação do texto segue-se inicialmente na tarefa de trazer um resgate histórico da teoria educacional.

${ }^{3}$ In TREVISOL, Maria Teresa C. Teoria e prática educativa. Aula proferida na Unoesc, Joaçaba, 25 de nov. 2013.

${ }^{4}$ Nossopedido de licença para registrar agradecimentos aos professores: Dra. Maria Teresa CeronTrevisol, Dr. Roque Strieder e Dr. Elton Luiz Nardi.

\section{REFERÊNCIAS}

AUSUBEL, David P. et alii. A importância da aprendizagem significativa na aquisição de conhecimento Psicologia Educacional. 2.ed. Rio de Janeiro: Interamericana, 1978. p. 54-57.

AUSUBEL, David P. et alii. Aprendizagem por recepção versus aprendizagem por descoberta Psicologia Educacional. 2.ed. Rio de Janeiro: Interamericana, 1978. p. 20-25.

BECKER, Fernando. Modelos Pedagógicos e Modelos Epistemológicos. InEducação e Construção do Conhecimento. Porto Alegre: Artmed, 2001. p. 15-32.

FURTADO, J. C. Entender como se aprende para aprender como se ensina. In WAJNSZTEJN, A. C. et alii (Org.) Desenvolvimento cognitivo e a aprendizagem escolar: o que o professor deve dominar para ensinar bem? Curitiba: Ed. Melo, 2010. 
HERNÁNDEZ, Fernando. A importância de saber como os docentes aprendem. InRevista Pátio - ano I, nº 04. Porto Alegre: Artmed, fev/abr - 1998. pp. 08-13.

LARANJEIRA, Maria Inês. Quem ensina, como aprende. InDa arte de aprender ao ofício de ensinar: relato, em reflexão, de uma trajetória. São Paulo: EDUSC, 2000. p. 103-114.

MANZINI, Eduardo José. Considerações sobre a transcrição de entrevistas. Disponível em «http://www.oneesp.ufscar.br/texto_orientacao_transcricao_entrevista». Acesso em: 19 nov. 2013.

MIZUKAMI, Maria da G. N. Abordagem comportamentalista. In MIZUKAMI, M. da G. Ensino: as abordagens do processo. São Paulo: EPU, 1986. P. 19-36.

MOURA, Ana Maria M.; AZEVEDO, Ana Maria P. \& MEHLECKE, Querte. As teorias de aprendizagem e os recursos da internet auxiliando o professor na construção do conhecimento. Disponível em «http://www.uel.br/seed/nte/as_teorias_de_aprendizagem_e_a_

internet.htm\#Teorias\%20da\%20Aprendizagem». Acesso em: $0 \overline{4}$ dez. 2013.

$\begin{array}{llll}\text { Normas de transcrição. } & \text { Disponível em }\end{array}$ «http://www.concordancia.letras.ufrj.br/index.php?option=com_content\&view=article \&id=52\&ltemid=58». Acesso em: 19 nov. 2013.

PIAGET, J. O tempo e o desenvolvimento intelectual da criança. In PIAGET, J. A Epistemologia Genética/ Sabedoria e ilusões da Filosofia/ Problemas de Psicologia Genética. 2. ed. São Paulo: Abril Cultural, 1983. p. 211-225.

PONTES, Ana Lúcia; REGO, Sérgio \& SILVA JR., Aluísio Gomes da. Saber e prática docente na transformação do ensino médio. InRevista Brasileira de Educação Médica. v. 30, n. 02, 2006, pp. 66-75. Disponível em «http://www.scielo.br/pdf/rbem/v30n2/v30n2a09.pdf». Acesso em: 04 dez. 2013.

POZO, Juan Ignácio. A sociedade da aprendizagem e o desafio de converter informação em conhecimento.InRevista Pátio. Porto Alegre: Artmed, ano VIII, n.13, Ago./Out.2004. p. 8-11.

RAMOZZI-CHIAROTTINO, Zélia. O conhecimento como resultado da interação entre o organismo e o meio - Psicologia e Epistemologia Genética de J. Piaget. São Paulo, EPU, 1988.

REGO, T. C. A cultura torna-se parte da natureza humana. InVygotsky: uma perspectiva histórico-cultural da educação. R. J: Vozes, 1995. p.37-83.

RONCA, Antonio C. C. O modelo de ensino de David Ausubel. In RONCA, Antonio C. C. Psicologia e Ensino. São Paulo: Papelivros, 1980, p. 59-83.

VALENTE, J. A. Criando oportunidades de aprendizagem continuada ao longo da vida. Revista Pátio - ano IV, n. 15. Porto Alegre: Artmed, nov.2000/jan - 2001. pp. 8-12.

VYGOTSKY, L.S. Internalização das funções psicológicas superiores. A Formação Social da Mente. 4. ed. São Paulo: Martins Fontes, 1991. p. 59-65. 
